\title{
The Effects of Annual Inflation Targets on the Conduct of Monetary Policy during the Disinflation Process in Mexico
}

\author{
Alfredo Cuevas and Jesus R. Gonzalez-Garcia* \\ acuevas@imf.org; jrgonzga@banxico.org.mx
}

November 2003

\begin{abstract}
We study the effects of the inflation targets established for December of each year on the conduct of monetary policy. The hypothesis tested postulates that the annual inflation targets could have produced some seasonality in the operation of the overnight interbank funds market in which the government funding rate is determined. To test this hypothesis a series of Taylor rules are estimated using linear and nonlinear methods. The results show that the inflation targets established for the end of year have special importance in the determination of the interest rate during the middle months of each year, and in the last quarter the focus of attention shifts to the target corresponding to December of the next year. Also, the results suggest that during the disinflation period, the short term interest rate has shown less inertia and more intense reactions to inflationary pressures during the central months of each year.
\end{abstract}

Keywords: Inflation targets; Markov-switching models; Mexico; Monetary Policy; Regime Switching models.

JEL classification: E31; E52; E58.

${ }^{*}$ Respectively, Economist of the International Monetary Fund and Economic Researcher of Banco de México. The authors are grateful for the suggestions and comments of Sara Castellanos, Daniel Chiquiar, Lorenza Martínez, Manuel Ramos, Julio Santaella, and Alberto Torres, as well as for the research assistance provided by Raquel Franco, Francisco Rivadeneyra, and Eduardo Rocha. This paper was written while Alfredo Cuevas was in Banco de México. The opinions contained in this paper are exclusively the authors' and do not necessarily reflect those of the IMF or Banco de México. 


\section{Contents}

1 Introduction 4

2 The Taylor Rule $\quad 6$

3 The Role of Annual Inflation Targets 8

4 Estimating Taylor Rules with Time-varying Indicators 10

5 Estimating Taylor Rules with Regime Changes 20

6 Conclusions and Final Comments $\quad 30$

$\begin{array}{lll}7 & \text { Appendix } & 35\end{array}$

\section{List of Tables}

1 Monetary Rules with Seasonality for the Government Funding Rate. Initial estimations using ordinary least squares. . . . . 13

2 Monetary Rules with Seasonality for the Government Funding Rate. Restricted nonlinear model. . . . . . . . . . . . 16

3 Monetary Ruels with Seasonality for the Government Funding Rate. Two-step restricted nonlinear model. . . . . . . . . . . 19

4 Estimation of the Monetary Rule with Regime Changes. . . . 21

5 Parameters of the Monetary Rule. . . . . . . . . . . . 22

6 Estimation of the monetary rule with regime changes. Using estimated series. . . . . . . . . . . . . . 28

7 Parameters of the Monetary Rule. Using the estimated series. 28

8 Estimation of the monetary rule with regime changes. Using the nonlinear inflation target. . . . . . . . . . . 38

9 Parameters of the Monetary Rule. Using the nonlinear inflation target. . . . . . . . . . . . . . . 38

\section{List of Figures}

1 Filter and Smoothed Probabilities. . . . . . . . . . . 23

2 Periods in which Regime 1 shows a probability greater than its unconditional probability. . . . . . . . . . . 24 
3 Proportion of total number of months in the sample in which Regime 1 has a probability greater than its unconditional

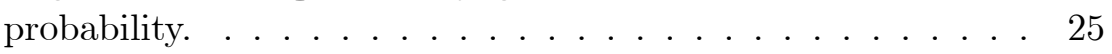

4 Estimation Errors. . . . . . . . . . . . . . . 27

5 Periods in which Regime 1 shows a probability greater than its unconditional probability. Using the estimated series. . . . 29

6 Linear and nonlinear inflation targets. . . . . . . . . . . 36

$7 \quad$ Difference between inflation gaps for the following 12 months with linear and nonlinear inflation targets. . . . . . . . . 37

8 Periods in which Regime 1 shows a probability greater than its unconditional probability. Using the nonlinear inflation target. . . . . . . . . . . . . . . . 39 


\section{Introduction}

Since the adoption of the floating exchange rate regime in December 1994, it has become increasingly obvious that monetary policy is now the nominal anchor of the Mexican economy. In particular, after a short period (19951996) in which limits were set on the expansion of the monetary base, and with the growing realization that fiscal policy was not going to play a dominant role, monetary policy has to an increasing extent been conducted in accordance with an inflation-targeting framework. During the disinflation process observed since the second half of the 1990s, that framework has been implemented by establishing annual inflation targets for the National Consumer Price Index (INPC) for December of each calendar year. The fact that the monetary authority operates in a context where targets are established for the end of the year suggests that the conditions under which it operatesand the scope for achieving those targets - are not uniform throughout the year.

This paper explores the possible effects of annual inflation targets on the conduct of monetary policy in Mexico in recent years. We first attempt to show that, during the disinflation process, the inflation targets for December of each year have taken on greater importance than they would have had if monetary policy had been directed at achieving inflation targets over moving time horizons of fixed duration. We also assess the reaction of short-term interest rates to inflationary pressures, and review the data for evidence of seasonal variations in that reaction.

It may be conjectured that, if special importance is attached to the inflation target for December of the current year, then monetary policy should be less tolerant when signs of inflationary pressures emerge in parts of the year other than those periods close to year-end. The reason for this is that, because the effects of monetary policy are produced with a lag, the greatest scope for influencing inflation to bring it into line with the target will be found several months before the end of the year. ${ }^{1}$ Thus, monetary policy might be expected to become more cautious at the end of the year, when annual inflation for that particular year is less sensitive to contemporaneous interest rates and the inflation target for the following year is still too remote to allow an accurate evaluation of the risks surrounding it. For the same reasons, such conduct might also be carried over into the beginning of the

\footnotetext{
${ }^{1}$ Martínez, Sánchez, and Werner (2001) use autoregressive vectors to estimate these lags. According to their findings, the first significant effects of the real interest rate on inflation occur after four months; the maximum impact comes at eight months; and after 10 months the effects are no longer statistically significant.
} 
following year. Generally speaking, the evidence presented in this paper would appear to support these assertions.

Our analysis focuses on the possible seasonality of the money market's behavior, which means that we need not concern ourselves with the specific dates of economic shocks that may have provoked reactions from the monetary authority. Consequently, the evidence presented here regarding seasonality in interest rate sensitivity to various indicators of inflationary pressures should not be taken to imply that there was any seasonal pattern to the major shocks that may have affected those rates. As examples of external shocks, we may point to the crises that broke out in Thailand and Korea at the end of 1997, the Russian crisis in the summer of 1998, and the Brazilian crisis of early 1999.

In exploring the hypotheses described above we use the Taylor rules, a methodology that involves analyzing specific determinants of the short-term interest rate. This methodology involves a certain risk of error in Mexico's case because Banco de México's operational target (the instrument) is not a specific level for the short-term interest rate, but an amount representing the balance of commercial banks' current accounts with the central bank (known as the corto or "short"). Under this system, short-term interest rates depend not only on the actions of the central bank but also on those of private transactors. In fact, the market may approximate the central bank's reaction function, which means that monetary conditions can change without necessarily entailing a change in the monetary policy instrument. In other words, it may be conjectured that there has been a specific pattern in the way monetary policy has been conducted, and that we can predict the effects of that pattern on the functioning of the money market; however, it is much more difficult to observe monetary conditions and attempt-based on a study of those conditions - to draw conclusions regarding the conduct of monetary policy. Nevertheless, the methodology based on monetary rules is still useful because the monetary authority monitors interest rates very closely to assess the degree to which they are consistent with the inflation target, and when it deems it necessary, the monetary authority will trigger changes in the rates trajectory by using the "short".

It must be noted that, while this paper focuses on Mexico's experience, its results might be borne out by the results observed in other countries. Its implications could help enhance the conduct of monetary policy by other central banks that have adopted inflation targeting and a gradual disinflation strategy. In this connection we might, for example, mention Chile, Slovakia, Greece, India, Israel, Peru, Poland, and Switzerland.

The remainder of the paper is organized as follows. The second section 
provides a brief review of the monetary rules methodology, while the third section explains how the problem of annual inflation targets is introduced into that methodology. The fourth section presents estimations of some models that seek to address the questions of (a) when the inflation target for the current year becomes relatively less important in determining the interest rate, and (b) whether it is possible to identify periods when the interest rate is more sensitive to changes in the various indicators of inflationary pressures. Our findings suggest that the interest rate has reacted more sharply to such pressures in the middle months of the year, and that in the final quarter of the year it becomes more sensitive to the inflation gap for the following year. In the fifth section we use techniques for estimating time series with regime changes to characterize the regimes under which money market interest rates seem to have been determined in recent years. That method allows us to identify endogenously the time at which changes in the intensity of the interest rate reaction occur, and to evaluate those changes. The results of this section confirm that during the disinflation period we can point to a degree of seasonality in the relationship between the interest rate and indicators of inflationary pressures, which is consistent with the restrictions and incentives created by the establishment of annual inflation targets. In the final section we present some conclusions, considering the fact that the disinflation process is drawing to a close.

\section{The Taylor Rule}

Taylor-type rules can fulfill a policy-making function when they are used as the basis for policy recommendations, and they can have another, positive meaning when they are estimated empirically. In the former case, the rule indicates what the monetary authority should be trying to achieve through its interventions in the money market. In the latter case, a monetary rule describes the relationship between short-term interest rate behavior and the movements of certain indicators of inflationary pressures. An exercise of this kind involves analyzing the behavior of the money market and, as a frequent additional step, attributing to the monetary authority the prime causal role in changes in money market conditions. In certain circumstances such a step seems natural, especially if the monetary policy instrument is a short-term interest rate. In the case of Mexico this may be a riskier course of action, because Banco de México does not determine the short-term interest rate.

The indicators of inflationary pressures commonly included in the Taylor rule are the inflation and output gaps. In addition, it is a generally accep- 
ted proposition in estimating Taylor rules that the interest rate behaves in accordance with a partial adjustment mechanism. Beyond the statistical usefulness of including an interest rate lag in the right hand side of the equation to be estimated, this mechanism has a ready-made interpretation. According to that interpretation, the monetary authority determines the desired level of the interest rate and takes the necessary steps to move the interest rate toward that level in a gradual manner. In other words, the assumption is that there is a mechanism whereby, for each period, a fraction of the difference between the observed interest rate and the desired interest rate is closed. ${ }^{2}$ In the case of monthly data, the basic model of the monetary rule can be expressed as follows:

$$
i_{t}=\rho i_{t-1}+(1-\rho)\left[r+\beta\left(E_{t}\left[\pi_{t+12}\right]-\pi_{t+12}^{o b j}\right)+\gamma\left(y_{t}-y_{t}^{p o t}\right)\right]+\varepsilon_{t}
$$

In equation (1), $i_{t}$ is the nominal interest rate, $E_{t}\left[\pi_{t+12}\right]$ is the expected inflation rate with a 12 -month horizon, $\pi_{t+12}^{o b j}$ is the inflation target for the same horizon, $y_{t}$ is observed output, and $y_{t}^{p o t}$ is potential output. This equation reflects the basic structure of the most popular models of the Taylor rule, although it is common to include other variables as well in the equation. The selection of those variables may differ considerably from one study to the next. In particular, the exchange rate is a natural candidate for inclusion, and it appears in some models such as those of Ball (1999) and Svensson (2000). Yet there is some controversy over the inclusion of the exchange rate: it has produced mixed results in various studies (Taylor, 2001) and, in the case of Mexico, as shown in Torres (2002), it does not appear to add anything meaningful to the information provided by the inflation and output gaps.

In equation (1), $\rho$ is the parameter for the partial adjustment mechanism and shows the inertia of the interest rate. $\beta$ represents the sensitivity of the interest rate to the deviations of inflation with respect to its target. If $\beta>$ 1 , an increase in the inflation gap generates a greater increase in the desired nominal rate, which will gradually be passed through into observed nominal rates. Thus, the ex ante real interest rate will rise to counter anticipated inflationary pressures. On the other hand, if $\beta<1$, the nominal rate will not rise in the same measure as expected inflation, the ex ante real interest rate will decline, and the deviation with respect to the inflation objective

\footnotetext{
${ }^{2}$ This interpretation of the partial adjustment mechanism is consistent with the gradual approach that Blinder (1998) advises central bankers to follow: "Decide what to do, and then do less."
} 
will tend to widen. Consequently, $\beta>1$ is a prerequisite for a stabilizing monetary policy. The $\gamma$ parameter in equation (1) reflects the interest rate's sensitivity to the output gap. A stabilizing policy is associated with $\gamma>0$, so that the interest rate will rise in the face of inflationary pressures associated with an above-potential level of output.

Even if we interpret the Taylor rule as a central bank reaction function, including the output gap in equation (1) does not necessarily mean that the central bank's objectives specifically include the pursuit of a given level of economic activity. The way in which the interest rate reacts to changes in the inflation and output gaps may depend on the type of disturbances affecting the economy. If both gaps are positive, we may infer that the economy has been suffering from excess demand, in which case a monetary policy response is imperative. If the inflation gap is positive and the output gap is negative, we may assume that there has been a negative supply shock, the inflationary effects of which should be temporary, because demand is reacting by contracting, so that a tighter monetary stance is not necessary. On the other hand, $\gamma>0$ could also indicate that monetary policy is pursuing multiple objectives. For example, in the event of a positive inflation gap and a negative output gap, a high value for $\gamma$ may mean that the desired interest rate is lower. In this case, the intention to avoid a recession will have taken priority over combating inflation. ${ }^{3}$ Finally, the $r$ parameter in equation (1) represents the steady-state interest rate level, as will be clear if the inflation and output gaps are set at zero.

\section{The Role of Annual Inflation Targets}

As noted earlier, during Mexico's disinflation period, the inflation targeting framework operated on the basis of explicit goals for annual inflation as measured in December of each year. We must therefore modify equation (1) in order to assess the role played by the targets established for December. A simple way of doing this is as follows:

$$
\begin{aligned}
i_{T, t}= & \rho i_{T, t-1}+(1-\rho)\left[r+\gamma\left(y_{t}-y_{t}^{p o t}\right)+\right. \\
& \left.\beta\left[\alpha\left(E_{T, t}\left[\pi_{T, d i c}\right]-\pi_{T, d i c}^{o b j}\right)+(1-\alpha)\left(E_{T, t}\left[\pi_{T+1, t}\right]-\pi_{T+1, t}^{o b j}\right)\right]\right] \\
& +\varepsilon_{T, t}
\end{aligned}
$$

${ }^{3}$ See Clarida, Galí, and Gertler (1999). 
In equation (2), the sub-indices $T$ and $t$ indicate, respectively, the year and the month to which each variable corresponds. ${ }^{4}$ In this equation, the parenthesis multiplying $\beta$ contains the weighted average of two inflation gaps. The first is the inflation gap defined with respect to the inflation target for December of the current year, while the second is the inflation gap defined with respect to a moving inflation target that has a horizon of 12 months. $\alpha$ is the weight given to the inflation gap for December of the current year.

Estimating a model like that in equation (2) for Mexico poses a problem for the analyst, in that the targets in recent years were defined explicitly only for December of each year. In other words, for the months of December there is a well-defined inflation target with a horizon of 12 months, while during the other 11 months of each year that target is not explicitly defined, but must be constructed as part of the analysis itself. Moreover, the inflation target for the following year, which is essential for constructing the series for the 12-month target, was generally announced in the second half of each year. In this paper, we have used the same convention as Torres (2002), and we have constructed the inflation target for the following 12 months by calculating the weighted average of two consecutive annual targets. ${ }^{5}$ On this point, there is no guarantee that the inflation targets thus constructed will coincide with the ones that the monetary authority may have adopted for horizons of 12 months over the period under consideration.

The adoption of inflation targets for December of each year may result in a degree of seasonality in the reaction of interest rates to indicators of inflationary pressures, because the monetary authority's stance with respect to this target will change over the course of the year. At the beginning of the year, the monetary authority may take steps that will have an undoubted impact on the level of prices during the year in order to meet the December target. Yet at this juncture it is rather difficult to estimate the magnitude of the risks surrounding the attainment of that target, because there will still be uncertainty as to the disruptions that might occur in the middle and later portions of the year. On the other hand, by the end of the year much of this uncertainty will have been resolved and the risks surrounding the target are better known, but by then it may be too late to act, because of the lags associated with the effects of monetary policy actions. ${ }^{6}$ To take a metaphor

\footnotetext{
${ }^{4}$ Naturally, in January of each year, when $t=1$, the lag is measured by $\mathrm{T}-1,12$.

${ }^{5}$ For example, in April 2001 the target for the following 12 months would be equal to 8/12 times the target for 2001 and 4/12 times the target for 2002 .

${ }^{6}$ This might suggest that the central bank should adjust its policy constantly, whenever there is a new shock. Yet such an approach could produce an erratic policy and might
} 
from game theory, it is as if the monetary authority were engaged in a duel with inflation for December, in which the rivals draw continuously closer to each other (Mehlmann, 2000). The monetary authority will not want to use up its ammunition too soon, while its rival is still far away and the shot might miss its mark; but neither will it want to wait too long, because the rival may shoot first. This metaphor suggests that monetary policy efforts might intensify once the monetary authority has a relatively clear idea of the risks associated with meeting the target for December, and while it still has time to act. On this basis, we can estimate a version of the monetary rule that allows the values of its parameters to deviate over the course of the year (with the exception of $r$, which by definition is constant). This version of the Taylor rule is shown in equation (3).

$$
\begin{aligned}
i_{T, t}= & \rho_{t} i_{T, t-1}+\left(1-\rho_{t}\right)\left[r+\gamma_{t}\left(y_{t}-y_{t}^{p o t}\right)+\right. \\
& \left.\beta_{t}\left[\alpha_{t}\left(E_{T, t}\left[\pi_{T, d i c}\right]-\pi_{T, d i c}^{o b j}\right)+\left(1-\alpha_{t}\right)\left(E_{T, t}\left[\pi_{T+1, t}\right]-\pi_{T+1, t}^{o b j}\right)\right]\right] \\
& +\varepsilon_{T, t}
\end{aligned}
$$

Equation (3) illustrates that the annual nature of inflation targets can have effects on the way the money market operates. These effects might be explained by changes in the circumstances under which monetary policy is being conducted. Specifically, the monetary policy stance may focus during a period of several months on achieving the target for the current year, in which case $\alpha$ would be relatively high in the initial and middle portions of the year. Nevertheless, as we approach the end of the calendar year, this attention may shift towards the inflation target 12 months out, and so $\alpha$ will decline in the latter months of the year. It is also possible to argue that, when attention is still focused on the current year's target and the monetary authority still has time to act, the reaction of the interest rate to changes in the inflation and output gaps could be relatively more intense, with a higher $\beta$, a higher $\gamma$, a lower $\rho$, or a combination of these changes. In the following sections we will estimate models for testing these assertions statistically.

\section{Estimating Taylor Rules with Time-varying In- dicators}

The first method for empirically testing the hypotheses mentioned above involves estimating equation (2) in order to establish the importance of the

undermine the institution's reputation. 
inflation target for December of the current year. Furthermore, in order to test the hypothesis that there is some seasonality in the determination of the interest rate on the money market, we also estimate two different versions of equation (3), using time-varying indicators (binary variables that take a value of one in the periods that interest us, and are zero the rest of the time), which serve to identify the central months of any given year.

Our sample runs from May 1997 to March 2003. The variables used in the estimations are the following:

1. The dependent variable is the monthly average of the weighted government Funding Rate. ${ }^{7}$

2. The output gap is equal to the percentage difference between observed output and potential output. Observed output is the seasonally adjusted series for the Global Index of Economic Activity (IGAE). A potential output series was estimated by applying the Hodrick-Prescott filter to the IGAE series, and another potential output series with a constant annual average growth rate of 4 percent was calculated. These two series were combined, assigning each a weight of 0.5 , to construct the potential output series used in the estimates. This approach to constructing the potential output series is designed to address the problem that the Hodrick-Prescott filter often creates at the beginning and at the end of the sample. ${ }^{8}$

3. The inflation gap series for the current year was constructed as the difference between the inflation rate for December of each year expected by the analysts surveyed by Banco de México and the target established for that date.

4. The future inflation gap is calculated as the difference between the inflation expectations of analysts surveyed by Banco de México for the following 12 months and a weighted average of inflation targets for the current year and the following calendar year, using as weights the

\footnotetext{
7 "Weighted" means that the daily rates result from the rates observed during the day weighted by the volume of transactions negotiated at those rates.

${ }^{8}$ We tested different specifications for the output gap, combining the HP filter with linear trends of different slopes, and varying the weights used to combine the filter and the linear trend. The linear trend selected is the one that appears best able to adjust the cyclical variation in economic activity during the period under analysis. Within certain limits, the choice of weights has no appreciable effect on the characteristics of the series being estimated, and thus produces no changes in the outcomes of this exercise.
} 
fraction of each of those years that is included in a moving horizon of 12 months. ${ }^{9}$

In estimating equations (2) and (3) it is useful to bunch their terms. Using $a_{i}$ to denote the coefficients to be estimated, those equations take the following reduced form:

$$
i_{T, t}=a_{0}+a_{1} i_{T, t-1}+a_{2} B P_{T, t}+a_{3} B I F_{T, t}+a_{4}\left(B I A C_{T, t}-B I F_{T, t}\right)+\varepsilon_{T, t}
$$

Here, $\mathrm{BP}$ is the output gap, BIAC is the inflation gap for the current year and BIF is the future inflation gap (for the following 12 months). On the basis of the $a_{i}$ estimated with equation (4), we can recover the parameters of the Taylor rule: $\rho=a_{1}, \gamma=a_{2} /\left(1-a_{1}\right), \beta=a_{3} /\left(1-a_{1}\right), \alpha=a_{4} / a_{3}$, and $r=a_{0} /\left(1-a_{1}\right)$.

Table 1 shows the outcomes of estimation where the condition $a_{4}=0$, which implies a conventional rule, is imposed (Model A) and also where $a_{4}$ is left free in order to demonstrate the importance of the inflation target established for December (Model B). This is a simple estimation using ordinary least squares and is used only as a first step. ${ }^{10}$ In this table, as in the rest of the paper, the levels of statistical significance are indicated with asterisks: three $(* * *)$ for 1 percent, two $(* *)$ for 5 percent, and one $\left(^{*}\right)$ for 10 percent. The corresponding $t$-statistics are shown in parentheses.

The middle portion of Table 1 shows the values for the monetary rule parameters recovered from the estimated coefficients. It will be noted that Model $\mathrm{B}$ rejects the hypothesis that $a_{4}=0$, which implies that the specification in which $a_{4}>0$ is preferable. In other words, it confirms the assumption that the inflation target for the current year is particularly important in determining interest rates.

Table 2 shows results for two preliminary estimations using time-varying indicators, i.e. binary variables for identifying selected quarterly and sixmonth periods. To make these estimates, we constructed variables that could identify seasonal impacts, by multiplying each explanatory variable from the

\footnotetext{
${ }^{9}$ It should be noted that analysts' inflation expectations may reflect certain anomalies; yet this does not affect the main findings of this paper, which are obtained from estimating the monetary rules with instrumental variables. This approach neutralizes any possible adverse statistical effects of such anomalies.

${ }^{10}$ Strictly speaking, equation (4) is a reduced form in which, using indirect least squares, we are estimating a system of equations constituting a Taylor rule given by equation (1) and an equation that defines the inflation gap as the weighted average of a gap 12 months hence and a gap for the current year.
} 
Table 1: Monetary Rules with Seasonality for the Government Funding Rate. Initial estimations using ordinary least squares.

\begin{tabular}{lcc}
\hline \hline & $\mathrm{A}$ & $\mathrm{B}$ \\
\hline Funding Rate, Lagged & $0.786^{* * *}$ & $0.6055^{* * *}$ \\
& $(12.92)$ & $(9.65)$ \\
Output Gap & $0.475^{* * *}$ & $0.883^{* * *}$ \\
& $(2.82)$ & $(5.39)$ \\
12-month inflation gap & $1.356^{* * *}$ & $2.061^{* * *}$ \\
& $(3.21)$ & $(5.36)$ \\
Difference between inflation & & $0.873^{* * *}$ \\
current year and 12 months & & $(5.11)$ \\
Constant & $1.309 * *$ & $3.321^{* * *}$ \\
& $(2.14)$ & $(5.09)$ \\
\hline Implicit value of $\alpha$ & 0.00 & 0.42 \\
Implicit value of $\beta$ & 6.32 & 5.21 \\
Implicit value of $\mathrm{Y}$ & 2.22 & 2.23 \\
Implicit value of $\rho$ & 0.79 & 0.60 \\
\hline Observations & 69 & 69 \\
$\mathrm{R}^{2}$ adjusted & 0.931 & 0.950 \\
\hline
\end{tabular}


model (4), including the constant, by indicators that take the value of 1 in the periods that are of interest, and that are zero for the rest of the year. This allows the $a_{i}$ coefficients to take different values at different times of the year, thereby letting the monetary rule parameters vary. In Model C, $a_{0}, a_{1}, a_{2}, a_{3}$, and $a_{4}$ are allowed to vary separately in the second and third quarters, in comparison to the period that includes the fourth quarter of one year and the first quarter of the next. On the other hand, in Model D they are allowed to vary in the period between April and September of each year with respect to the period October-March. This latter period we shall call, for the sake of convenience, the "base period". ${ }^{11}$

The models of Table 2 are designed to identify changes in the Taylor rule parameters during the intermediate months of the year, with respect to the base period. In this respect, it is advisable to observe the variation in the $\alpha$ parameter throughout the year. This parameter measures the relative weight of the inflation gap for the current year within the average inflation gap, which also includes the inflation gap for the following 12 months. This parameter is difficult to identify in the first months of the year. The reason is that in those months there is an high degree of overlap between the currentyear inflation gap and the 12-month inflation gap. Because of this, in the basic regime the estimated value of this parameter reflects the weighting given to the inflation target for the current year in the closing months of the year. Those are the months that contribute the most to identifying this parameter.

The models shown in Table 2 were estimated with nonlinear least squares, because of the need to impose a nonlinear restriction on the parameters in order to ensure that the level of the implicit long-term interest rate remains constant throughout the year. That rate is represented by $r$ in equation (3) and is equal to $a_{0} /\left(1-a_{1}\right)$, in terms of the coefficients of equation (4). Thus, while $a_{0}$ and $a_{1}$ are allowed to vary, they must do so in such a way that the value of the expression $a_{0} /\left(1-a_{1}\right)$ remains constant. This requirement was met with a restriction on the variability of $a_{0}$, i.e., on the value of the coefficients of the seasonal indicator variables alone (with no interaction with the explanatory variables). ${ }^{12}$

\footnotetext{
${ }^{11}$ The specification described in the text was obtained from more general preliminary estimations in which the coefficients could change every quarter. It must be noted that the set of variables defined as interactions between the regressors and the seasonal indicators is sufficiently broad to ensure that we can identify separately the time-varying patterns for each original parameter of the Taylor rule.

${ }^{12}$ In the various estimation exercises described in this section, the value of the long-term interest rate was around 7 percent.
} 
Table 2 is divided vertically into three panels: the first contains the estimated coefficients, the second indicates some statistical tests, and the third presents the parameters recovered from the coefficients. For each of the models estimated (referred to as C and D), Table 2 shows three columns. The first column presents the estimated coefficients or parameters, the second column the statistics for evaluating the degree of significance of the values in the first column, while the third column indicates the marginal probability of the statistics in the second column. In the table, the expressions T2 and T3 indicate the second and third quarters, respectively.

The main general conclusion from the top panel is that, in nearly all cases, the interactions of the indicators for the selected periods with the key variables have the expected signs and are statistically significant. For example, coefficients for the interactions between the binary variables and the interest rate lag are always negative, which may be interpreted as a decline in the inertia of interest rate movements during the middle months of the year.

The middle panel of Table 2 shows various statistics. The first test of interest seeks to verify the hypothesis that the monetary rule parameters are equal in the second and third quarters. In this case, the F statistic rejects, with a 5 percent significance level, the hypothesis that in both quarters the parameters are equal, which suggests that model $\mathrm{C}$ is better than model D. The second test is used to verify that the presence of possible endogenous variables is not a problem. The output gap, while contemporaneous, is constructed using filters that include future values for output, which may be affected by the contemporaneous level of the interest rate. Furthermore, the inflation gaps are calculated using expectations of future inflation, which could be affected by the contemporaneous level of the interest rate. The null hypothesis of the Hausman test is that the output and inflation gaps are exogenous with respect to the interest rate (or rather, that any potential problem of endogeneity is empirically irrelevant). This hypothesis is rejected at 5 percent significance in model $\mathrm{C}$ and at 1 percent in model $\mathrm{D}$. The foregoing points to the need for a procedure using instrumental variables to correct the problem of endogeneity. As noted below, we opted for an estimation using two-stage least squares (non-linear and restricted). Before discussing this estimation, some comments on the lower panel of Table 2 are in order.

The results from the lower panel of Table 2 suggest that the way in which interest rates react in the face of inflationary pressures has reflected some degree of seasonality in recent years. This panel shows values for the original parameters that can be retrieved using estimated coefficients, as 
Table 2: Monetary Rules with Seasonality for the Government Funding Rate. Restricted nonlinear model.

\begin{tabular}{|c|c|c|c|c|c|c|}
\hline \multirow{2}{*}{ I. Estimation of Reduced Forms } & \multicolumn{3}{|c|}{$\mathrm{C}$} & \multicolumn{3}{|c|}{$\mathrm{D}$} \\
\hline & Coefficient & t-Stat. & Mg. Prob. & Coefficient & t-Stat. & Mg. Prob. \\
\hline Lagged Funding Rate & 0.739 & 9.98 & 0.00 & 0.734 & 9.42 & 0.00 \\
\hline With indicator T2 & -0.683 & -2.51 & 0.01 & & & \\
\hline With indicator T3 & -0.225 & -1.74 & 0.08 & & & \\
\hline With Indicator April-September & & & & -0.332 & -2.77 & 0.01 \\
\hline Output Gap & 0.568 & 2.88 & 0.00 & 0.576 & 2.79 & 0.01 \\
\hline With indicator $\mathrm{T} 2$ & 1.595 & 2.68 & 0.01 & & & \\
\hline With indicator T3 & 0.297 & 0.86 & 0.39 & & & \\
\hline With Indicator April-September & & & & 0.717 & 2.37 & 0.02 \\
\hline 12- month Inflation Gap & 1.296 & 2.68 & 0.01 & 1.269 & 2.55 & 0.01 \\
\hline With indicator T2 & 4.073 & 2.16 & 0.03 & & & \\
\hline With indicator $\mathrm{T} 3$ & 2.131 & 2.98 & 0.00 & & & \\
\hline With Indicator April-September & & & & 2.120 & 3.18 & 0.00 \\
\hline $\begin{array}{l}\text { Difference between current-year } \\
\text { and } 12 \text {-month inflation gaps }\end{array}$ & 0.337 & 2.05 & 0.04 & 0.362 & 2.06 & 0.04 \\
\hline With indicator T2 & 2.842 & 2.85 & 0.00 & & & \\
\hline With indicator T3 & 1.065 & 3.47 & 0.00 & & & \\
\hline With Indicator April-September & & & & 1.459 & 4.85 & 0.00 \\
\hline Constant & 2.023 & 3.41 & 0.00 & 2.179 & 3.31 & 0.00 \\
\hline \multicolumn{7}{|l|}{ II. Statistics } \\
\hline Observations & \multirow{3}{*}{\multicolumn{3}{|c|}{$\begin{array}{r}69 \\
0.967\end{array}$}} & \multicolumn{3}{|c|}{69} \\
\hline $\mathrm{R} 2$ adjusted & & & & \multicolumn{3}{|c|}{0.963} \\
\hline Test F Autocorrelation & & & \multirow{2}{*}{$\begin{array}{l}0.45 \\
0.05\end{array}$} & \multicolumn{2}{|c|}{$\mathrm{F}(1,58)=0.058$} & 0.81 \\
\hline Test F Restriction $\mathrm{T} 2=\mathrm{T} 3$ & \multicolumn{2}{|c|}{$\begin{array}{l}\mathrm{F}(1,54)=0.571 \\
\mathrm{~F}(4.56)=2.565\end{array}$} & & & & \\
\hline \multirow[t]{2}{*}{ Test F Exogeneity } & $\mathrm{F}(9,40)=$ & .291 & 0.04 & $\mathrm{~F}(6,47)=$ & 2.989 & 0.01 \\
\hline & \multicolumn{3}{|c|}{$\mathrm{C}$} & \multicolumn{3}{|c|}{$\mathrm{D}$} \\
\hline \multirow[t]{2}{*}{ III. Original Parameters } & \multicolumn{3}{|c|}{ Stability Test } & \multicolumn{3}{|c|}{ Stability Test } \\
\hline & Param. & Chi (1) & Mg. Prob. & Param. & Chi (1) & Mg. Prob. \\
\hline \multicolumn{7}{|l|}{ Value of $\boldsymbol{\alpha}$} \\
\hline In T3 & 0.41 & 1.02 & 0.31 & 0.54 & 2.80 & 0.09 \\
\hline In T2 & 0.59 & 5.71 & 0.02 & 0.54 & & \\
\hline Rest of year & 0.26 & & & 0.29 & & \\
\hline \multicolumn{7}{|l|}{ Value of $\beta$} \\
\hline In T3 & 7.05 & 4.46 & 0.03 & 5.66 & 1.44 & 0.23 \\
\hline In T2 & 5.69 & 0.82 & 0.37 & 5.66 & & \\
\hline Rest of year & 4.96 & & & 4.77 & & \\
\hline \multicolumn{7}{|l|}{ Value of $\mathbf{Y}$} \\
\hline In T3 & 1.78 & 0.45 & 0.50 & 2.16 & 0.00 & 1.00 \\
\hline In T2 & 2.29 & 0.06 & 0.81 & 2.16 & & \\
\hline Rest of year & 2.18 & & & 2.16 & & \\
\hline \multicolumn{7}{|l|}{ Value of $\rho$} \\
\hline In T3 & 0.51 & 3.04 & 0.08 & 0.40 & 7.70 & 0.01 \\
\hline In T2 & 0.06 & 6.28 & 0.01 & 0.40 & & \\
\hline Rest of year & 0.74 & & & 0.73 & & \\
\hline
\end{tabular}


well as the $\chi^{2}$ statistics corresponding to Wald tests. In these tests, the null hypothesis is that the original parameters have the same value in the key period as six months earlier. For model D, this is a simple test of the mid-year regime against the base period; in the case of model $\mathrm{C}$, the test compares quarters 2 and 3 separately against the base regime. With respect to parameter $\alpha$, what we are told about the base period relates in reality to the fourth quarter since, as noted earlier, information from the first quarter is of virtually no help in identifying the value of $\alpha$ in the base period. As might be expected, $\alpha$ increases in the middle of the year and declines at the end of the year, probably reflecting the fact that the central bank's capacity to influence compliance with the target for the current year is greatly reduced in the last quarter, at which time it shifts its attention to the inflation target of the coming year. In column $\mathrm{C}$, the parameter changes associated with the output gap, $\gamma$, appear to be strongest in the second quarter, while the parameter changes for the coefficients associated with the average inflation gap, $\beta$, appear strongest in the third quarter. This suggests that the interest rate becomes more sensitive to these indicators in the middle of the year, albeit in a sequence indicating that the output gap is more of a leading indicator of inflationary pressures than is the inflation gap. This point is intuitively reasonable, since inflationary pressures represented by the output gap operate on inflation with greater lags. Nevertheless, we must note that the parameter associated with the output gap does not seem to vary in a statistically significant manner. Finally, the value of $\rho$ declines in the middle months of the year, indicating that interest rate changes become less gradual. In model $\mathrm{D}$, for example, the average life of a discrepancy between the observed interest rate and the desired interest rate during the base period is nearly 70 days, while for the period April-September it is only 23 days.

The results of a two-step estimation of the Taylor rules are shown in Table 3. As noted earlier, evidence from Hausman tests suggests that it is best to estimate the model with instrumental variables. As a first step, we obtained estimated values for the output gaps $\left(B P^{e}\right)$, inflation for the current year $\left(B I A C^{e}\right)$ and future inflation $\left(B I F^{e}\right)$. These values were obtained from regressions of $B P, B I A C$ and $B I F$ against the lagged interest rate and a series of predetermined instruments. ${ }^{13}$ One reason for select-

\footnotetext{
${ }^{13}$ These instruments were: growth in the industrial output index for the United States (lags 1, 2, and 3); monthly inflation (lags 1 to 3,6 and 9), inflation gaps for the current year and the following 12 months (lags 1 to 3,6 , and 9), and lags 4, 5, and 6 of the output gap. For this last series we used only distant lags to ensure that they were predetermined, since potential output is constructed using a centered moving average.
} 
ing the two-step estimation approach was precisely in order to obtain $B P^{e}$, $B I A C^{e}$ and $B I F^{e}$, and to use these regressors, free of endogeneity problems, in the estimations for Section 5 of this paper.

The design of Table 3 is similar to the design of Table 2, with the difference that the Hausman test is now excluded. In general terms, the upper panel is very similar in the two tables. The greatest innovation in the midportion of Table 3 is the test for the hypothesis that quarters 2 and 3 are equal, which cannot be rejected at a significance level of 5 percent. Because of this, model $\mathrm{F}$ is probably preferable to model $\mathrm{E}$. The foregoing indicates that it is sufficient to postulate the existence of only two regimes: one for the October-March period, and the other for the intermediate months of the year.

The lower panel of Table 3 shows again that $\alpha$ declines in the fourth quarter. The magnitude of the decline is similar to what was estimated in the models of Table 2. Yet this time the difference is not statistically significant. Apparently, by using instrumental variables we have sacrificed some accuracy in estimating the change of emphasis from the current year to the next. On the other hand, as with Table 2, there is no significant change in the parameter associated with the output gap.

The most striking results from models $\mathrm{E}$ and $\mathrm{F}$ have to do with the seasonality of the parameters $\rho$ and $\beta$. These parameters record changes that have the expected sign and are statistically significant. Those changes suggest that the reaction of the interest rate intensifies in the middle months of the year, when the inflation target for the year is still a priority. In particular, in the middle of the year, $\beta$ tends to rise and $\rho$ to decline. In other words, the interest rate response to an increase in the inflation gap is more intense and makes itself felt more swiftly. To put it another way, there would seem to be two factors contributing to a greater tightening in monetary conditions in the intermediate months of the year: on the one hand, the difference between the observed interest rate and the desired rate is narrowed more quickly, and on the other hand, the desired rate tends to be more sensitive to the inflation gap.

According to these results, the sensitivity of interest rates is greater in the middle of the year, reacting more vigorously to fluctuations in the inflation gap (and to a lesser extent in the output gap), and becoming less gradual. This outcome is highly intuitive. Given the lags with which monetary policy operates (from 4 to 10 months, as noted above), the middle portion of the year seems to be a good time to take action to influence the inflation that will be observed at the end of the calendar year. On the other hand, in the first quarter of the year there are greater possibilities of error in forecasting 
Table 3: Monetary Ruels with Seasonality for the Government Funding Rate. Two-step restricted nonlinear model.

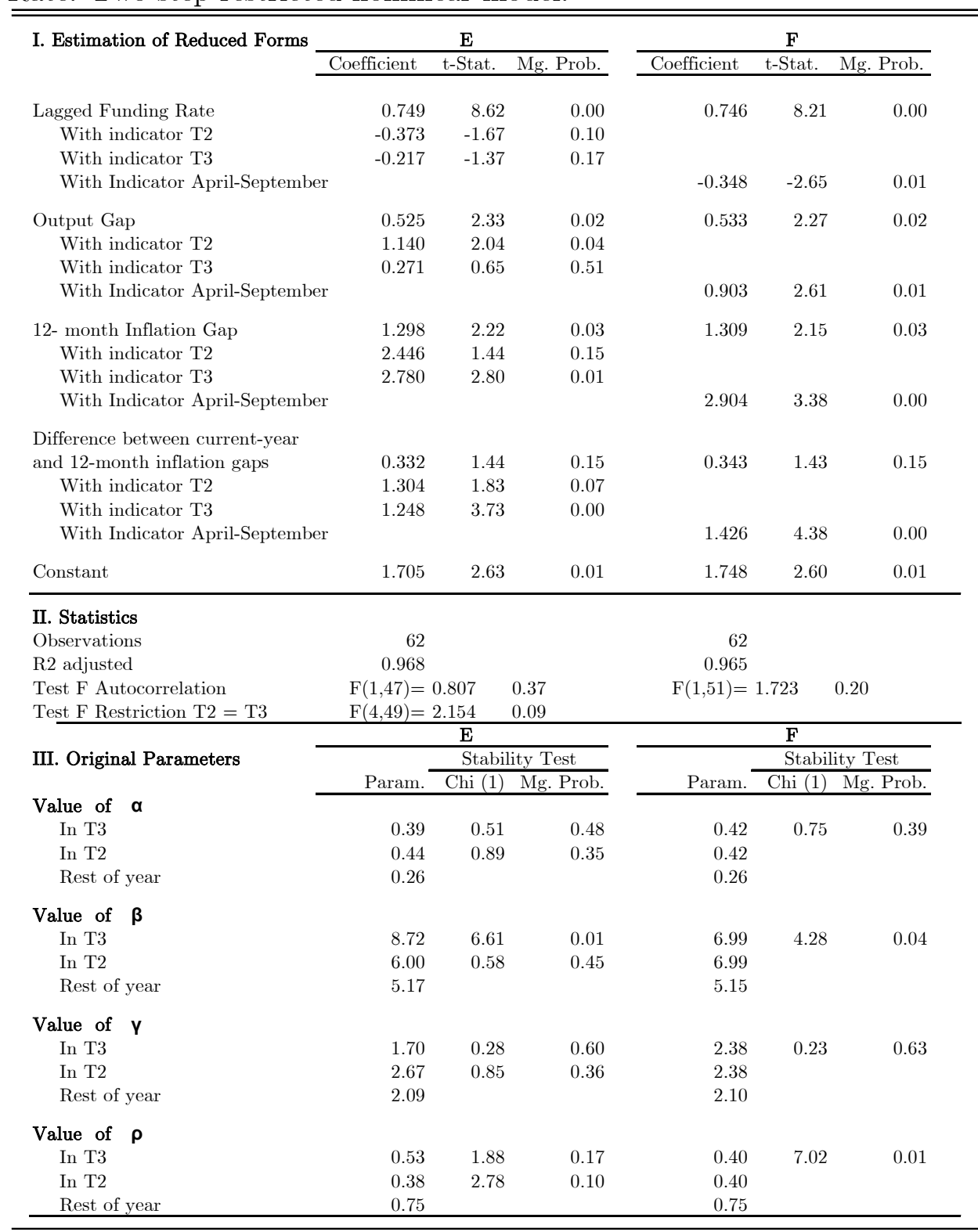


inflation for the current year, while the fourth quarter contains a similar risk in forecasting the inflation gap for the coming 12 months, which by this quarter will have become the priority objective. Therefore, the interest rate should react more strongly to inflationary pressures in the April-September period.

\section{Estimating Taylor Rules with Regime Changes}

An alternative way of testing whether the setting of annual inflation targets may induce some seasonality in the reaction of the interest rate to inflationary pressures is to estimate Taylor rule parameters using the methodology proposed by Hamilton $(1989,1994)$. This method facilitates the endogenous identification of changes over time in the monetary rule parameters. In this way we can characterize the various regimes under which the money market may have been operating, and we can show how those regimes alternate during the period under consideration. Each regime is defined by the values associated with the basic parameters of the monetary rule, while the periods in which each regime predominates are identified by estimating the probabilities that each of those regimes has prevailed at each date of the sample.

The estimated model has the same structure as equation (4). To represent regime changes, that model can be written as:

$$
\begin{aligned}
i_{T, t}= & a_{0, j}+a_{1, j} i_{T, t-1}+a_{2, j} B P_{T, t}+a_{3, j} B I F_{T, t} \\
& +a_{4, j}\left(B I A C_{T, t}-B I F_{T, t}\right)_{T, t}+\varepsilon_{j, T, t}
\end{aligned}
$$

where $j(=1,2)$ represents the regime under which the money market is operating in month $t$. The transition between regimes is described as a first order Markov chain with constant transition probabilities, $p_{j, j}$, and is represented by the following transition matrix:

$$
P_{j, j}=\left[\begin{array}{cc}
p_{1,1} & p_{2,1}=1-p_{2,2} \\
p_{1,2}=1-p_{1,1} & p_{2,2}
\end{array}\right]
$$

In this last expression, $p_{1,1}$ represents the probability that the money market will remain under regime 1 between the dates $T, t$ and $T, t+1$, while $p_{1,2}$ represents the probability that it will shift from regime 1 to regime 2 .

The estimations in this section make no assumption as to the periods in which changes in the monetary rule parameters occur. The dates on which those changes occur will be inferred on the basis of the filtered and smoothed 
Table 4: Estimation of the Monetary Rule with Regime Changes.

\begin{tabular}{|c|c|c|c|c|c|c|}
\hline & \multicolumn{3}{|c|}{ Regime $\mathrm{j}=1$} & \multicolumn{3}{|c|}{ Regime $\mathrm{j}=2$} \\
\hline$a_{0, j}$ & $\begin{array}{c}\text { Estimator } \\
2.28\end{array}$ & $\begin{array}{c}\text { t-Stat. } \\
4.59\end{array}$ & $\begin{array}{c}\text { Mg. Prob. } \\
(0.000)\end{array}$ & $\begin{array}{c}\text { Estimator } \\
6.49\end{array}$ & $\begin{array}{c}\text { t-Stat. } \\
6.86\end{array}$ & $\begin{array}{c}\text { Mg. Prob. } \\
(0.000)\end{array}$ \\
\hline$a_{1, j}$ & 0.74 & 15.02 & $(0.000)$ & 0.12 & 1.47 & $(0.146)$ \\
\hline$a_{2, j}$ & 0.56 & 4.32 & $(0.000)$ & 2.08 & 9.02 & $(0.000)$ \\
\hline$a_{3, j}$ & 1.21 & 3.57 & $(0.001)$ & 5.06 & 11.38 & $(0.000)$ \\
\hline$a_{4, j}$ & 0.41 & 3.06 & $(0.003)$ & 3.10 & 11.97 & $(0.000)$ \\
\hline$p_{j, j}$ & 0.82 & 1.54 & $(0.129)$ & 0.49 & 0.56 & $(0.578)$ \\
\hline$\sigma_{j}^{2}$ & 0.94 & 9.41 & $(0.000)$ & 0.94 & 9.41 & $(0.000)$ \\
\hline
\end{tabular}

probabilities that either regime is prevalent at any given point in time. The filtered probability in a given month is estimated using information from observations on that date and previous dates, while the smoothed probability is estimated using information from the entire sample. Because of this fact, the smoothed probability is a better indicator of the prevalence of each regime at each date of the sample.

Note that the Hamilton method presupposes that the Markovian process represented by the transition matrix is stationary and ergodic. Strictly speaking, this estimation method is not designed for explicitly modeling periodic Markovian processes, which would represent the case at hand more closely if we assume that the hypotheses we are seeking to test are correct. Nevertheless, the estimation strategy adopted in this section takes advantage precisely of the assumption of stationarity, thereby avoiding the intrusion of the analyst's beliefs about the portions of the year in which the money market operates under a particular regime. With use of this methodology, the statistical procedure identifies the months in which data behavior suggests the presence of a particular regime, and we then seek to visualize a pattern in the estimated regime changes that might suggest some kind of seasonality. Table 4 presents results from the estimations, and Table 5 shows the parameters that are of interest. ${ }^{14}$ Figure 1 shows the filter and smoothed probabilities that the money market is operating under regime 1.

According to the results from Table 5, under regime 1 there is greater

\footnotetext{
${ }^{14}$ As can be seen, in our estimation we imposed the restriction that the error variance is the same under both regimes. That restriction was accepted after testing with a more general model where all parameters are allowed to change over time. In the general model we also tested the restriction that the constant is equal under both regimes. This hypothesis was rejected.
} 
Table 5: Parameters of the Monetary Rule.

\begin{tabular}{cccc}
\hline \hline & Regime $\mathrm{j}=1$ & Regime $\mathrm{j}=2$ & \\
\hline$\rho_{j}$ & 0.743 & 0.121 & $* * *$ \\
$\gamma_{j}$ & 2.174 & 2.366 & \\
$\beta_{j}$ & 4.693 & 5.757 & $* *$ \\
$\alpha_{j}$ & 0.337 & 0.613 & $* * *$ \\
\hline
\end{tabular}

inertia in the behavior of the interest rate: the coefficient of the interest rate of the previous period is 0.74 , while under regime 2 it declines to 0.12 . This decline is statistically significant at 1 percent. On the other hand, under regime 1 the interest rate reaction to the output gap has a value of 2.2 , while under regime 2 this rises to 2.4. Nevertheless, this change is not statistically significant. As well, the interest rate reaction to the inflation gap is less under regime 1 than under regime 2 (4.7 and 5.8, respectively), and the importance of the inflation gap for the current year under regime 1 is 0.34 , rising to 0.61 under regime 2 . These changes are statistically significant.

In short, regime 2 is characterized by less inertia in the interest rate and greater impact on the interest rate resulting from the output and inflation gaps. Under regime 2, the inflation gap for the current year is more important than the inflation gap for the following 12 months in determining the interest rates. 
Figure 1: Filter and Smoothed Probabilities.

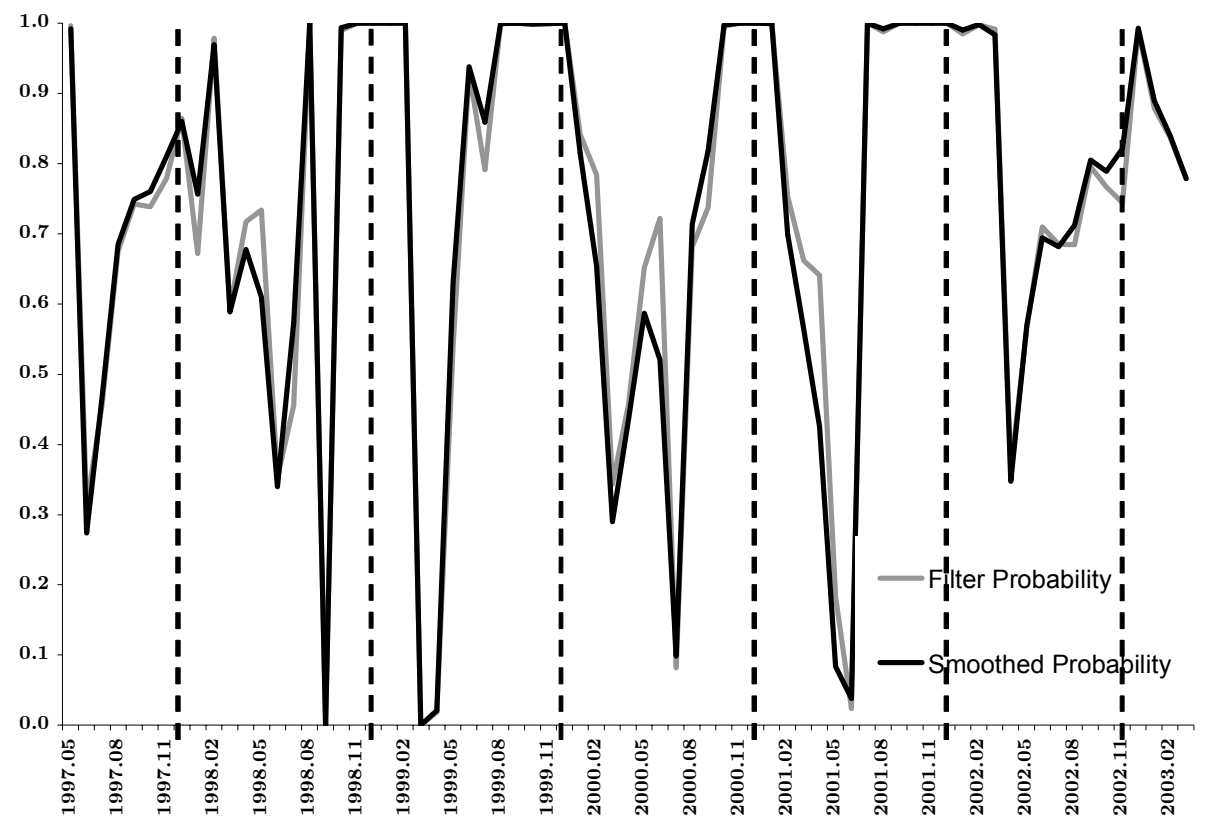

Generally speaking, regime 1, which we might call the basic regime, was predominant during the sample period, with an unconditional probability of $0.74 .^{15}$ This means that, on average, only one of every four months is characterized by regime 2 and so we may regard this regime as a temporary tightening in money market conditions. In Figure 2, the months of December of each year are marked with dotted lines and the filtered and smoothed probabilities that regime 1 prevails on any given date of the sample period are shown. As can be seen, regime 1 tends to prevail at the end of each year, while regime 2 appears more frequently at midyear. Although the episodes

\footnotetext{
${ }^{15}$ In the Hamilton method, unconditional (or ergodic) probabilities of regimes represent the long-term forecast of the Markov chain, and are independent of the regime under which the system is operating at present. Furthermore, by implication, they represent the frequency with which each regime will be observed over an arbitrarily long period of time. This latter idea is more in keeping with the nature of the hypotheses proposed in this paper: it reflects the fact that, in the extreme case, if there were irreducible seasonality in the system analyzed, there would be no ergodic distribution of prevalence of the different regimes. The regimes would succeed one other according to a certain periodicity, right into the indefinite future. Yet, even in this case, we may say that there is a limit to the proportion of observations corresponding to one or other regime.
} 
in which regime 2 appears to prevail do not occur at exactly the same time each year, it is clear that they occur toward the middle of the year, and not at the beginning or end of the year.

To illustrate the seasonality with which the money market appears to have operated in recent years, Figure 2 shows, by means of the gray areas, the periods in which the smoothed probability that the system is in regime 1 is greater than the unconditional probability of that regime, while the white areas show the periods in which the probability of regime 2 is greater than its unconditional probability. As can be seen, the periods in which regime 1 predominates tend to be concentrated at the turn of the calendar year, while the periods in which regime 2 predominates tend to be concentrated between the months of March and August. This suggests that during that time the interest rate has shown less inertia, and has reacted more intensely to changes in the inflation gap, and that the inflation gap for the current year is more important in determining the interest rate.

Figure 2: Periods in which Regime 1 shows a probability greater than its unconditional probability.

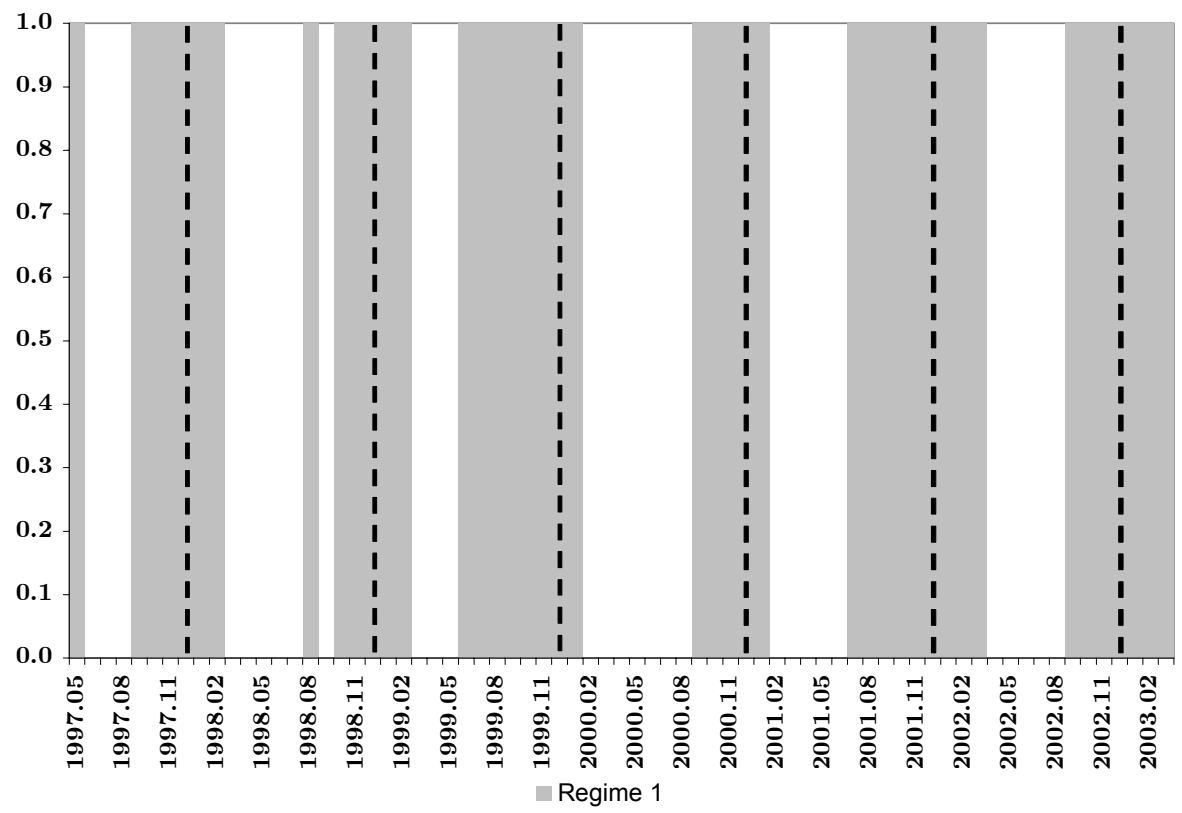


The foregoing results are presented in a more concise format in Figure 3 , which shows, for each month of the year, the proportion of the number of months in the sample in which the smoothed probability of regime 1 exceeded its unconditional probability. For example, for the month of January, a value of 1 is shown, meaning that in all months of January the smoothed probability of regime 1 was greater than its unconditional probability. ${ }^{16}$ The proportions corresponding to regime 1 are equal to unity between October and January and reach their lowest values ( 0.5 or less) between March and August. The foregoing suggests that in the middle months of the year the interest rate has reacted more intensely to changes in the indicators of inflationary pressures.

Figure 3: Proportion of total number of months in the sample in which Regime 1 has a probability greater than its unconditional probability.

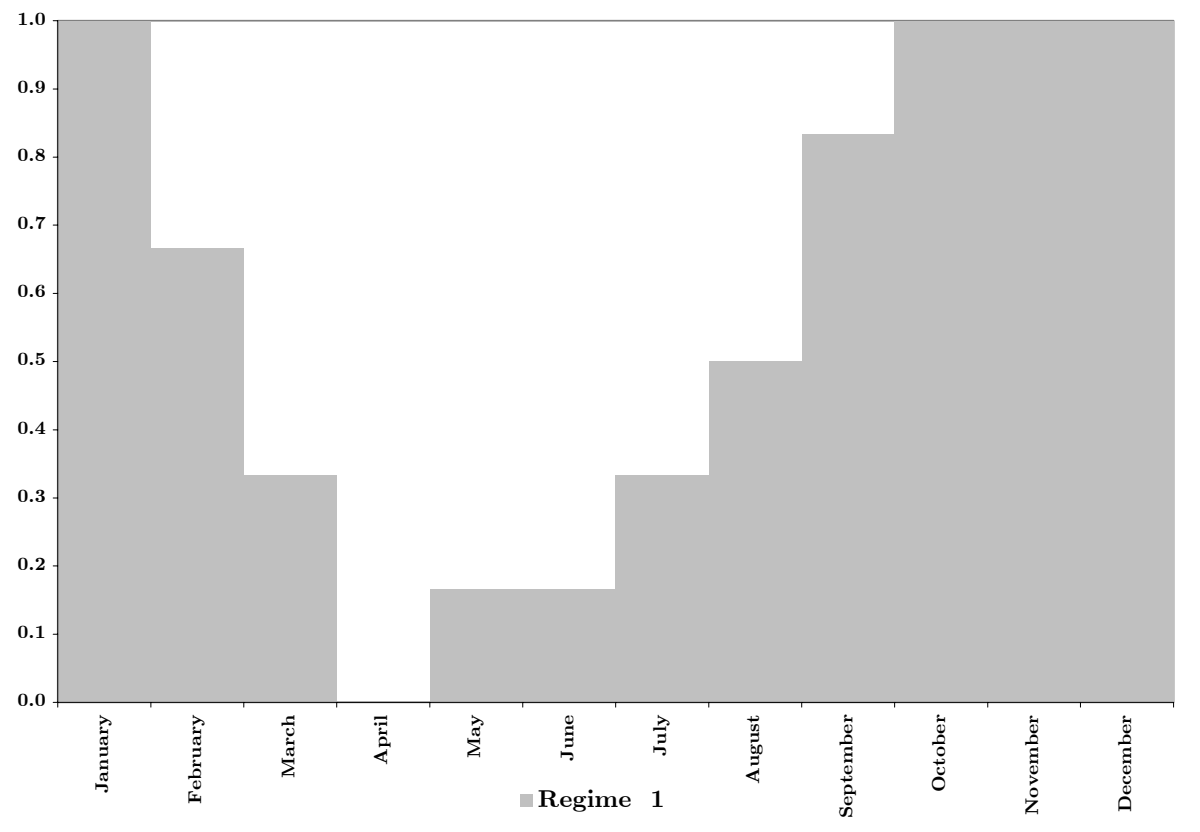

The seasonality identified is not rigid, as can be seen in the transition

\footnotetext{
${ }^{16}$ The comparison was made using the smoothed probability, because this is a better estimator of the probability that a given regime prevails at any given point, as discussed above.
} 
from the year 2002 to 2003. As Figure 1 clearly shows, regime 1 is not present in this transition with the same forcefulness as in the other yearly transitions. The probability of regime 1 in this last transition is greater than its unconditional probability, and yet, with the exception of December 2002 , it is far from being equal to 1 . This suggests that, on that particular occasion, money market conditions were tighter than they normally are at the beginning and end of the year. The reason for this behavior was that the central bank saw the need to send a signal indicating that, while the target for 2002 might appear increasingly difficult to achieve because of temporary factors, the commitment to return inflation as quickly as possible to its programmatic path had not been abandoned. ${ }^{17}$

Figure 4 shows estimation errors for two models: a linear model, such as that of column B of Table 1, and a nonlinear model with regime changes. As can be seen, the nonlinear model's errors are generally smaller than those of the linear model. The model with regime changes produces a mean quadratic error considerably smaller than the linear model (0.84 versus 2.43 ).

Also, in a formal test for comparing these two models, the linear model is rejected in favor of the model with regime changes. The test in question is a likelihood ratio test, in which the linear model represents the null hypothesis and the model with regime changes represents the alternative. Because some parameters (such as the transition matrix elements) are not defined under the null hypothesis, we must correct the marginal probability corresponding to the test statistic $\chi^{2}$ resulting from the likelihood ratio (see Hall et al., 1997). The test statistic mentioned is equal to twice the difference between the logarithm of the likelihood function of the regime-change model and that of the linear model: $2 *(-114.59+132.73)=36.29$ and is represented as $2 \mathrm{~h}$. This statistic has a marginal probability of 0.000006 , with 7 degrees of freedom (corresponding to the number of parameters reported in any of the columns of Table 4). The needed correction to this probability is obtained by adding the value of $\left[2 h^{(n / 2)}\right] /\left[e^{h} \Gamma(n / 2)\right]$ where $2 \mathrm{~h}$ is the test statistic mentioned, $\mathrm{n}$ is the number of degrees of freedom and $\Gamma($.$) represents the$ gamma function. This correction produces an adjusted probability of 0.0002 , indicating rejection of the null hypothesis according to which the 7 additional parameters of the model with regime changes are supposedly redundant.

\footnotetext{
${ }^{17}$ In February 2002, sharp increases were announced in certain administered prices, particularly for electricity. The magnitude of these increases was the primary obstacle to achieving the year-end target for 2002 as may be inferred from the fact that, if the increase in administered and "negotiated" prices had been 4.5 percent (i.e., the same as the inflation target), the annual inflation in the INPC would have been 4.6 percent, instead of 5.7 percent. See Banco de México (2003).
} 
Figure 4: Estimation Errors.

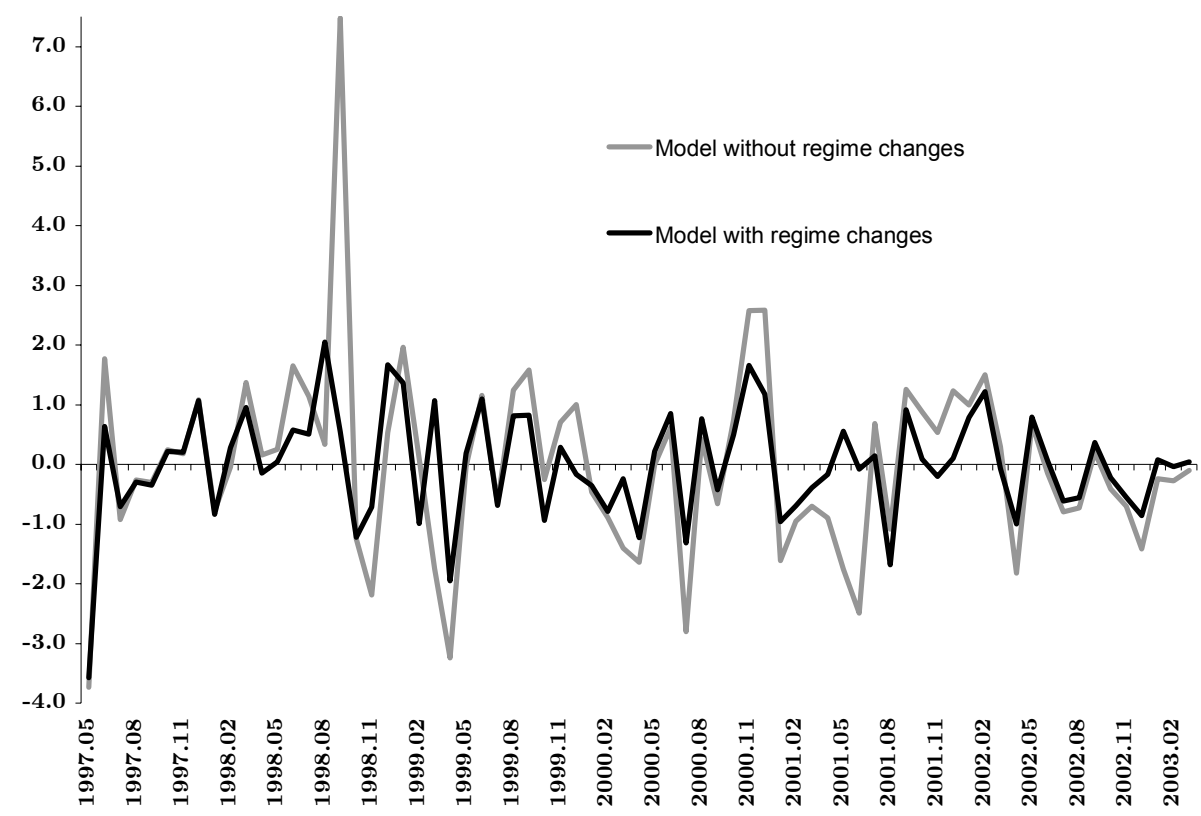

We also estimated the Taylor rule with regime changes, using in the right side of equation (5) the series $B P^{e}, B I F^{e}$ and $B I A C^{e}$, constructed for the two-step estimation of the previous section. The estimation results are reported in Table 6 , and the values of the parameters of interest in Table 7. Figure 5 presents the proportion of the total number of months in the sample in which regime 1 has a probability greater than its unconditional probability.

The results are similar to those obtained above. In Table 7 , regime 2 shows less inertia in the interest rates ( $\rho$ declines from 0.77 to 0.07 ) and greater impact on the interest rate resulting from the output and inflation gaps ( $\gamma$ increases from 2.20 to 2.87 and $\beta$ from 4.53 to 5.76). These changes are statistically significant. Also, in regime 2 the inflation gap for the current year is more sizable than the inflation gap for the following 12 months ( $\alpha$ rises from 0.45 to 0.53 ). Nevertheless, this increase is not statistically significant. As in the previous estimation, regime 1 is predominant, with an unconditional probability of 0.83 . The most important difference between the two estimations lies in the identification of the period in which regime 2 prevails, as shown in Figure 5. In this case, the occurrence of regime 
Table 6: Estimation of the monetary rule with regime changes. Using estimated series.

\begin{tabular}{cccccccc}
\hline \hline & \multicolumn{3}{c}{ Regime $\mathrm{j}=1$} & & \multicolumn{3}{c}{ Regime $\mathrm{j}=2$} \\
\cline { 2 - 4 } \cline { 6 - 8 } & Estimator & t-Stat. & Mg. Prob. & & Estimator & t-Stat. & Mg. Prob. \\
$a_{0, j}$ & 2.07 & 3.77 & $(0.000)$ & & 6.61 & 6.10 & $(0.000)$ \\
$a_{1, j}$ & 0.77 & 13.18 & $(0.000)$ & & 0.07 & 0.78 & $(0.438)$ \\
$a_{2, j}$ & 0.52 & 3.63 & $(0.001)$ & & 2.67 & 5.61 & $(0.000)$ \\
$a_{3, j}$ & 1.06 & 3.00 & $(0.004)$ & & 5.36 & 8.45 & $(0.000)$ \\
$a_{4, j}$ & 0.48 & 3.12 & $(0.003)$ & & 2.85 & 9.69 & $(0.000)$ \\
$p_{j, j}$ & 0.89 & 1.37 & $(0.176)$ & & 0.46 & 0.56 & $(0.574)$ \\
$\sigma_{j}^{2}$ & 0.87 & 7.86 & $(0.000)$ & & 0.69 & 2.95 & $(0.004)$ \\
\hline \multicolumn{1}{l}{$\log$ of the likelihood function: -95.405 }
\end{tabular}

Table 7: Parameters of the Monetary Rule. Using the estimated series.

\begin{tabular}{cccc}
\hline \hline & Regime $\mathrm{j}=1$ & Regime $\mathrm{j}=2$ & \\
\hline$\rho_{j}$ & 0.766 & 0.069 & $* * *$ \\
$\gamma_{j}$ & 2.202 & 2.870 & $* *$ \\
$\beta_{j}$ & 4.533 & 5.760 & $*$ \\
$\alpha_{j}$ & 0.450 & 0.532 & \\
\hline
\end{tabular}

2 , in which money market conditions are temporarily tightened, is concentrated between March and May, while in the previous estimation that period extended from March to August. 
Figure 5: Periods in which Regime 1 shows a probability greater than its unconditional probability. Using the estimated series.

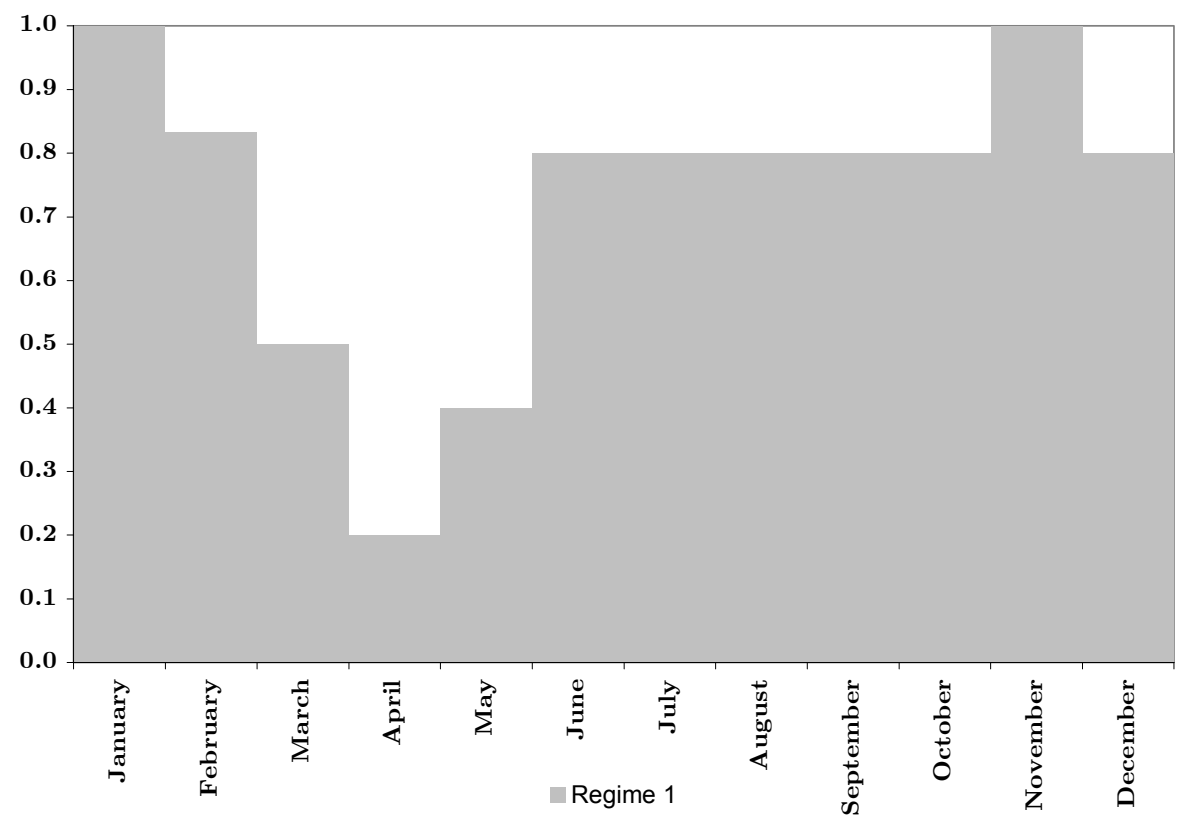




\section{Conclusions and Final Comments}

Monetary policy in Mexico became the nominal anchor of the economy upon adoption of the floating exchange rate, and it has operated within a disinflation strategy that has set increasingly strict inflation targets for the end of each year. Achieving those targets has been fundamental to consolidating the credibility of Banco de México.

Using the methodology of Taylor rules, this paper has shown, first, that during the disinflation process of recent years the annual inflation targets set for December of each year have been more important than they would have been if monetary policy had been directed at achieving inflation targets over moving, fixed-length time horizons. The paper has also shown that the strongly annual focus of the inflation targets may have encouraged the emergence of a seasonal pattern in the money market. Given the importance of achieving the December target, the response of the interest rate to the inflation and output gaps, and the speed of its adjustment, appear to have been most pronounced in the middle portion of each year.

By applying the (restricted nonlinear) least squares method in two steps, we find that, during the period under consideration (May 1997 to March 2003), the interest rate was more sensitive to variations in the inflation gap, and it fluctuated less gradually between April and September of each year. Moreover, the importance of the inflation gap for the current year in determining interest rates appears to decline in the final quarter of each year (although this result is statistically less compelling).

We also estimated monetary policy rules allowing for regime changes and found that in recent years there has been an alternation between a regime that might be called "basic" and another regime that is more sharply antiinflationary. Under this latter regime, the interest rate reacts more intensely to changes in inflationary indicators, and the inflation gap for the current year is more important than the inflation gap with a 12-month horizon. This latter regime generally appeared at some time between March and August of each year; although 2002 appears to have been somewhat atypical, since there are signs of a tightening reaction in interest rates at the end of that year as well.

In short, the evidence that the interest rate reaction to inflationary pressures was sharper at midyear is robust in the face of changes in the estimation method, and is unrelated to the particular dates of disturbances that might have prompted interest rate changes.

These results, which are derived directly from the estimation of various models using different techniques, call for some further comments. The first 
is that those results can be explained in terms of two factors that may have generated a degree of seasonality in the determination of the short-term interest rate, in a context where the annual inflation target for December represents a focal point in the discussion of the economy's performance. On the one hand, as the year progresses we can estimate more accurately the potential deviations from the December target, while on the other hand, the later an action is taken in the year the lower the likelihood that the interest rate change will contribute to achieving the target for the current year. Consequently, the middle months of the year is the most favorable period for changes in the interest rate to contribute to achieving the December inflation target: for in the middle part of the year, the possible deviation of inflation from the year-end target is better known, and there is still time to shift monetary policy in the desired direction.

Yet, given the institutional characteristics of Mexico, we may ask to what extent the evidence presented here might justify taking account of seasonal changes in monetary policy. The monetary policy instrument used in the Taylor rules presented in this paper is the Government Funding Rate, which is determined by the overnight interbank funds market. Nevertheless, the visible decisions regarding monetary policy in Mexico are the announced changes in the target for banks' current account balances, or changes in the "short". In this sense, for example, the models estimated here would seem difficult to reconcile with such facts as the absence of changes in the "short" for prolonged periods. The resolution to this apparent contradiction lies in the fact that the interest rate is the result of monetary conditions that change over time, and that the central bank can influence those conditions at any moment by changing the "short". Thus, if money market conditions are such that a change in the "short" does not seem necessary, the central bank will not change it, but interest rates will represent the level that the monetary authority considers consistent with its inflation target; otherwise, it would take action. Moreover, it is possible that the market may internalize the central bank's reaction function, thereby producing a change in monetary conditions without the need for the central bank to change the level of the "short".

The second consideration relates to the outlook for monetary policy. It is quite possible that the seasonality demonstrated by the money market in recent years could disappear in the future. In the first place, the effects of annual inflation targets have resulted from the fact that Mexico has undergone a gradual disinflation process during which successive annual targets entailed additional reductions in inflation, and the central bank has had to rebuild its inflation-fighting reputation. Yet Mexico is currently on the 
verge of steady-state inflation, and expectations are that inflation at end2003 will not differ by more than one percentage point from its long-term target. Consequently, once the disinflation stage is over, the value (in terms of the central bank's reputation) of achieving a specific target in December (or in any other given month) will be reduced. This situation should also be seen in the context of the institutional change that is to occur in 2004 . After December 2003, Banco de México will abandon its practice of setting annual targets for December, and the goal of monetary policy will be to keep annual inflation as measured by the INPC permanently at a level of 3 percent, plus or minus one percentage point. This institutional change will tend to eliminate the difference that has existed between the importance attached to December's inflation and the inflation rate for other months.

The third, and more general, consideration has to do with the lessons that may be drawn for the conduct of monetary policy in other countries that have adopted inflation targeting and a gradual disinflation strategy based on the establishment of periodically observable goals. In this respect, the most significant implication of this paper is that the monetary authority can take fuller advantage of the conditions prevailing on the money market at certain times of the year in order to achieve its targets. Nevertheless, it must be recognized that this will only be possible if communication between the central bank and money market participants is such that the latter can internalize to a large extent both the objectives and the reaction function of the central bank so that their participation in the market will help to create conditions whereby the monetary authority can maximize the effectiveness of its policy measures. 


\section{References}

[1] Ball, L. (1999), "Policy Rules for Open Economies", in Taylor, J. (ed.), Monetary Policy Rules, University of Chicago Press, pp. 127-144.

[2] Banco de México (2002), Informe sobre la Inflación Abril-Junio 2002 [Inflation Report, April-June 2002], Mexico City, Banco de México.

[3] Banco de México (2003), Informe sobre la Inflación Octubre-Diciembre 2002 y Programa Monetario para 2003 [Inflation Report, October-December 2002 and Monetary Program for 2003], Mexico City, Banco de México.

[4] Blinder, A. (1998), Central Banking in Theory and Practice, Cambridge, MIT Press.

[5] Calvo, Guillermo A., "Staggered Prices in a Utility-Maximizing Framework," Journal of Monetary Economics, 12 (September 1983): 383-398.

[6] Castellanos, S. (2000), "El efecto del corto sobre la estructura de tasas de interés" [The impact of the "short" on the structure of interest rates], Mexico City, Banco de México, research paper 2000-1.

[7] Clarida, R., Gali, J., and Gertler, M. (1999), "The Science of Monetary Policy: A New Keynesian Perspective", in Journal of Economic Literature, v. 37, n. 4, 1661-1707.

[8] Díaz de León, A. and Greenham, L. (2000), "Política Monetaria y Tasas de Interés: Experiencia Reciente para el Caso de México" [Monetary policy and interest rates: recent Mexican experience], Mexico City, Banco de México, research paper $2000-8$.

[9] Hall, S., Psaradakis, Z. and Sola, M. (1997), "Cointegration and Changes in Regime: The Japanese Consumption Function", Journal of Applied Econometrics, 12, 151-168.

[10] Hamilton, J. D. (1989), "A New Approach to the Economic Analysis of Nonstationary Time Series and the Business Cycle", Econometrica, 57, 357-384.

[11] Hamilton, J. D. (1994), Time Series Analysis. Princeton University Press, Princeton, NJ.

[12] Martínez, L., Sánchez, O., and Werner, A. (2001), "Consideraciones sobre la Conducción de la Política Monetaria y el Mecanismo de Transmisión en 
México" [Thoughts on the conduct of monetary policy and the policy transmission mechanism in Mexico], Mexico City, Banco de México, research paper 2001-02.

[13] Mahadeva, L. and Sterne, G. (2002), "The Role of Short-run Inflation Targets and Forecasts in Disinflation," London, Bank of England, Working Paper No. 167.

[14] Mehlmann, A. (2000), The Game's Afoot!: Game Theory in Myth and Paradox. Providence. American Mathematical Society. 159 p.

[15] Svensson, L. (2000), "Open-Economy Inflation Targeting," in Journal of International Economics, v. 50, n. 1, pp.155-183.

[16] Taylor, J. (1999), "A Historical Analysis of Monetary Policy Rules," in Taylor, J. (ed.), Monetary Policy Rules, University of Chicago Press, pp. 319-348.

[17] Taylor, J. (2000), "Using Monetary Policy Rules in Emerging Market Economies" in Banco de México, Stabilization and Monetary Policy: The International Experience (75th Anniversary Seminar), pp. 441-457.

[18] Taylor, J. (2001), "The Role of the Exchange Rate in Monetary-Policy Rules," in American Economic Review, v. 91, n. 2, pp. 263-267.

[19] Torres, A. (2002), "Un Análisis de las Tasas de Interés en México a través de la Metodología de Reglas Monetarias" [An analysis of interest rates in Mexico using the monetary rules methodology], Mexico City, Banco de México, research paper No. 2002-11.

[20] Wooldridge, J. (2002), Econometric Analysis of Cross Section and Panel Data, Cambridge, MIT press. 


\section{Appendix}

As explained in Section 2, for December of each year there is a clearly defined annual inflation target for the INPC with a 12-month horizon, while during the remaining 11 months of the year analysts must generate their own 12month inflation targets. In this paper we have adopted the convention used by Torres (2002), and have constructed the inflation gap for the following 12 months as the difference between the expectations of private-sector analysts surveyed by Banco de México and an inflation target that is the weighted average of two consecutive annual targets, where the weights are the fraction of each year that is covered in the 12-month horizon. In other words, inflation targets for the period from January to November each year were obtained by linear interpolation. In graphic terms, we joined the targets for December of each year with straight lines.

In order to verify whether the construction of the inflation target for the following 12 months, as described above, introduces a bias in the estimation of monetary rules and in the seasonality they demonstrate, we constructed an alternative series for the 12-month inflation target. That "nonlinear" series was constructed taking into account the seasonal pattern of monthly inflation rates up to the previous year, and the targets established for December of each year. Figure 6 shows the series for the linear inflation target, and the series that takes account of the seasonality of monthly inflation rates. As can be seen, there are some differences between the linear and the nonlinear inflation targets. Specifically, in recent years the linear inflation target seems to have been higher than the nonlinear inflation target during the first half of each year, and slightly below it during the second half of the year.

Given the differences between the linear and "nonlinear" inflation targets, the inflation gap for the following 12 months may vary depending on the inflation target used. These differences are shown in Figure 7. As will be seen, when the linear inflation target is higher than the "nonlinear" one, the inflation gap for the following 12 months is lower, and if the linear inflation target is lower than the "nonlinear" one, the inflation gap for the following 12 months is greater. This may suggest that the differences described above could induce a bias in the estimation of the seasonality of the monetary rule. 
Figure 6: Linear and nonlinear inflation targets.

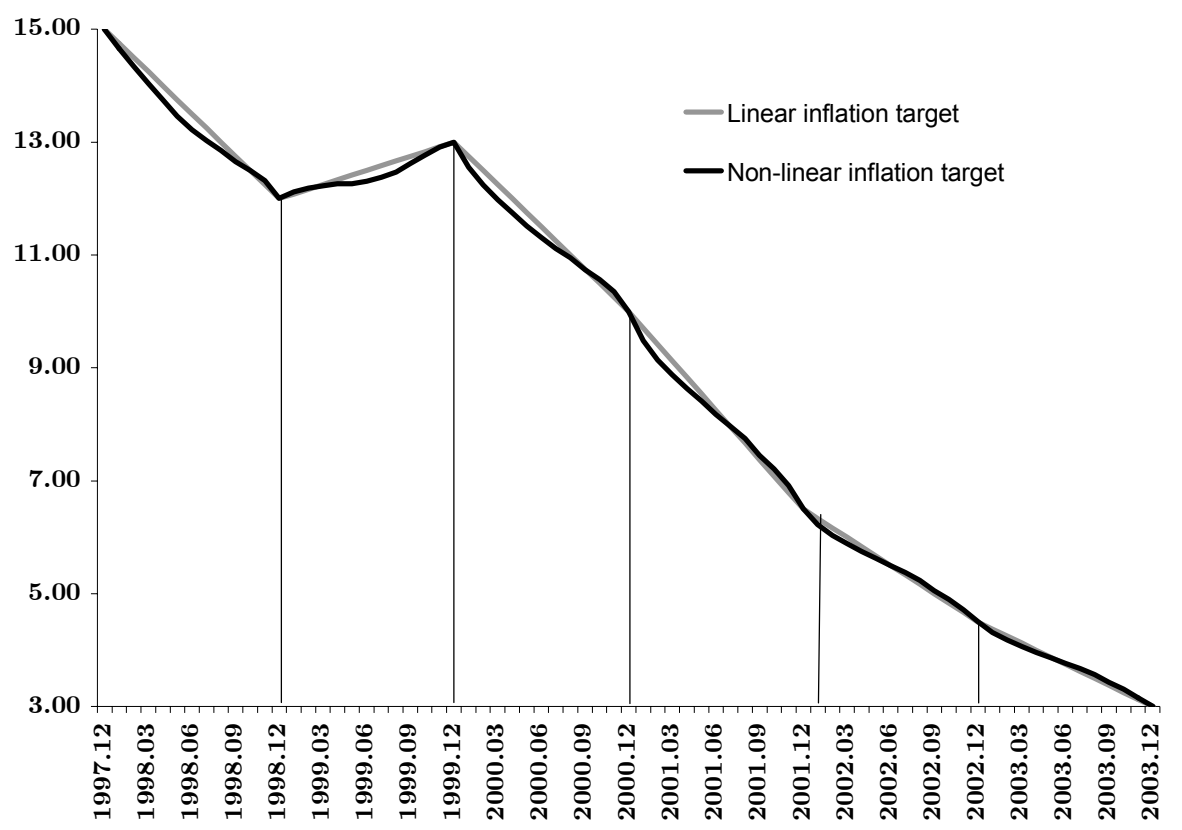


Figure 7: Difference between inflation gaps for the following 12 months with linear and nonlinear inflation targets.

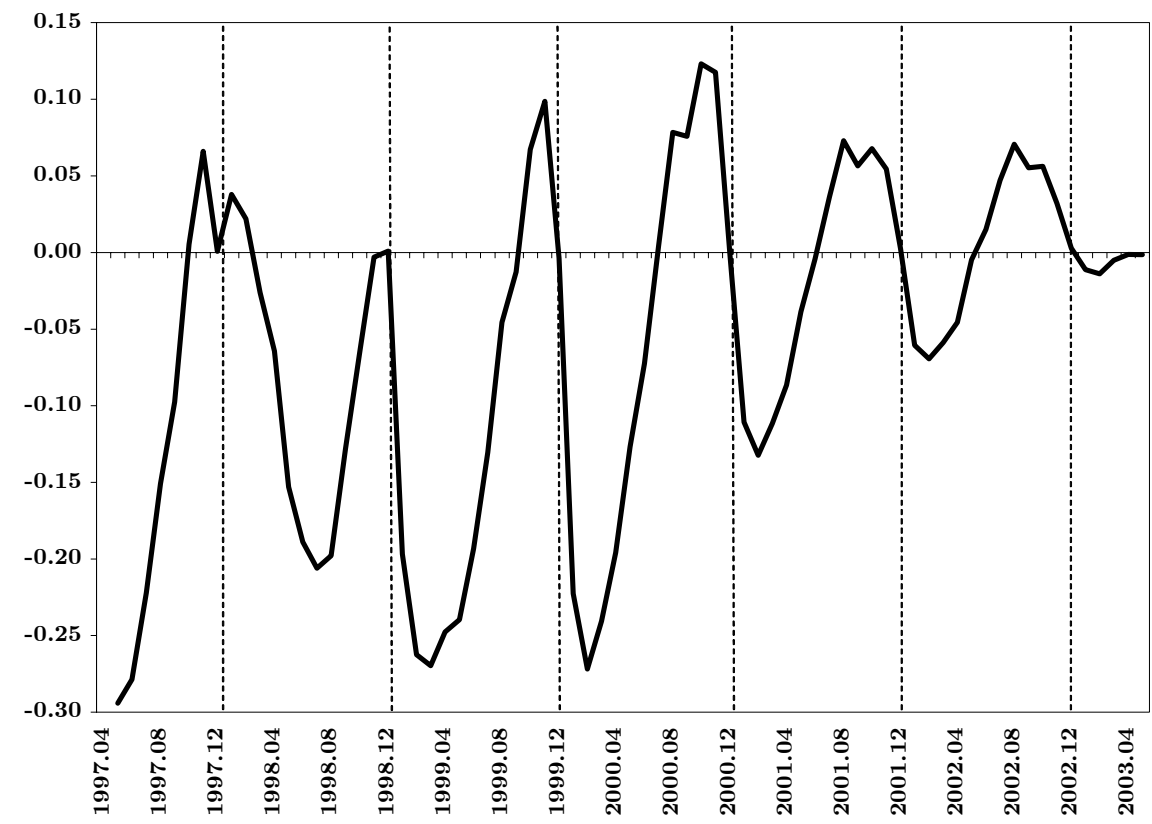

In estimating the monetary rule with regime changes, using the inflation gap constructed with the "nonlinear" inflation target, we find that construction of the linear inflation target does not introduce any bias in the estimation and it is not the cause of the seasonal changes in the Taylor rule parameters that were reported in the body of this paper.

Table 8 shows the results of estimating the monetary rule with regime changes considering the inflation gap for the following 12 months, using the "nonlinear" inflation target, while Table 9 shows the corresponding original parameters of the monetary rule in each regime. Figure 8 shows the proportion of the number of months in the sample in which regime 1 has a probability greater than its unconditional probability.

The magnitude of changes in the parameters over the year are very similar to those obtained in the original model, and the seasonality demonstrated by the parameters of the monetary rule over the year is also very close to that in the original estimation reported in the body of this paper. Thus, the results verify that the construction of the linear inflation target 
Table 8: Estimation of the monetary rule with regime changes. Using the nonlinear inflation target.

\begin{tabular}{|c|c|c|c|c|c|c|}
\hline & \multicolumn{3}{|c|}{ Regime $\mathrm{j}=1$} & \multicolumn{3}{|c|}{ Regime $\mathrm{j}=2$} \\
\hline$a_{0, j}$ & $\begin{array}{c}\text { Estimator } \\
2.27\end{array}$ & $\begin{array}{c}\text { t-Stat. } \\
4.41\end{array}$ & $\begin{array}{c}\text { Mg Prob. } \\
(0.000)\end{array}$ & $\begin{array}{c}\text { Estimator } \\
6.68\end{array}$ & $\begin{array}{c}\text { t-Stat. } \\
6.29\end{array}$ & $\begin{array}{c}\text { Mg Prob } \\
(0.000)\end{array}$ \\
\hline$a_{1, j}$ & 0.75 & 14.83 & $(0.000)$ & 0.10 & 1.05 & $(0.298)$ \\
\hline$a_{2, j}$ & 0.54 & 4.02 & $(0.000)$ & 2.06 & 7.67 & $(0.000)$ \\
\hline$a_{3, j}$ & 1.08 & 3.43 & $(0.001)$ & 5.03 & 10.34 & $(0.000)$ \\
\hline$a_{4, j}$ & 0.42 & 3.24 & $(0.002)$ & 3.12 & 10.89 & $(0.000)$ \\
\hline$p_{j, j}$ & 0.83 & 1.52 & $(0.134)$ & 0.46 & 0.49 & $(0.628)$ \\
\hline$\sigma_{j}^{2}$ & 1.01 & 9.70 & $(0.000)$ & 1.01 & 9.70 & $(0.000)$ \\
\hline
\end{tabular}

Table 9: Parameters of the Monetary Rule. Using the nonlinear inflation target.

\begin{tabular}{cccc}
\hline \hline & Regime $\mathrm{j}=1$ & Regime $\mathrm{j}=2$ & \\
\hline$\rho_{j}$ & 0.752 & 0.099 & $* * *$ \\
$\gamma_{j}$ & 2.177 & 2.285 & \\
$\beta_{j}$ & 4.361 & 5.586 & $* *$ \\
$\alpha_{j}$ & 0.389 & 0.621 & $* *$ \\
\hline
\end{tabular}

for the 12-month horizon is not the source of the seasonality demonstrated by the monetary rule parameters. 
Figure 8: Periods in which Regime 1 shows a probability greater than its unconditional probability. Using the nonlinear inflation target.

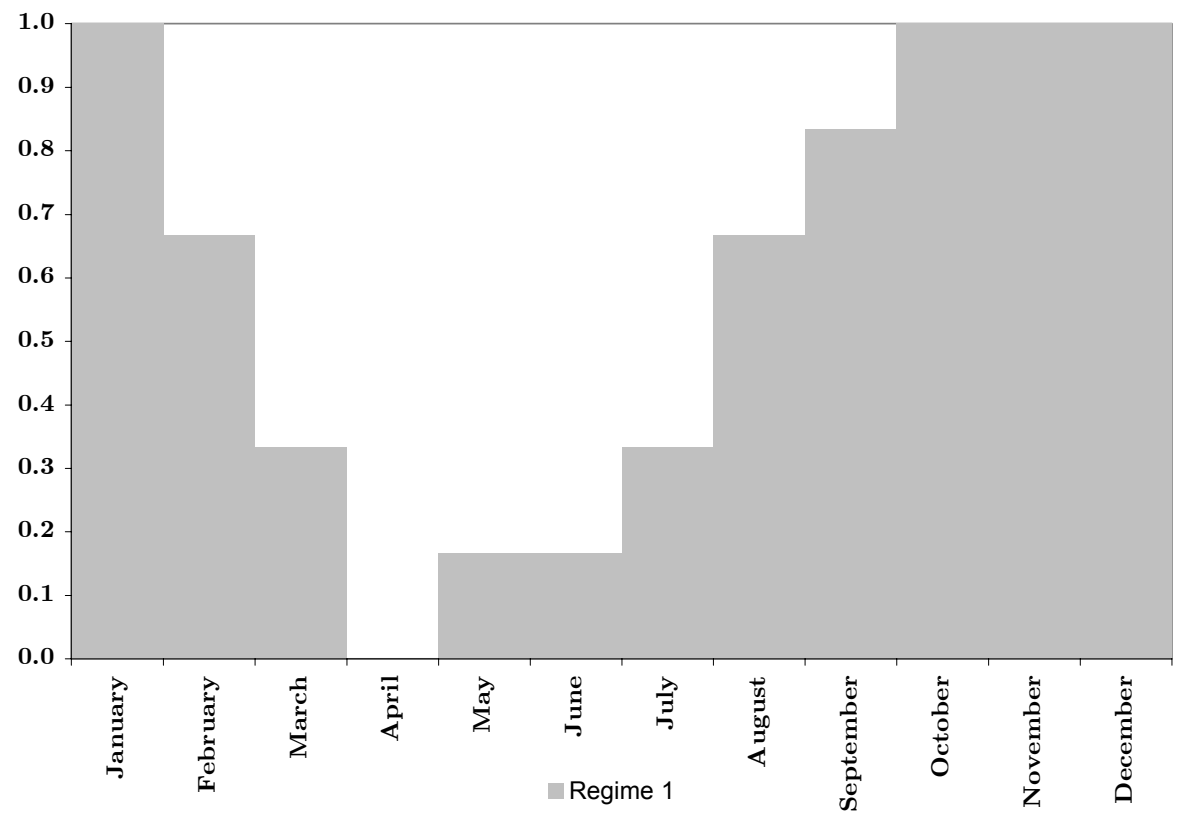

